\title{
Use of Electronic Resources in Scholarly Electronic Journals: A Citation Analysis
}

\section{Susan Davis Herring}

\begin{abstract}
Although information gathering and use patterns in the traditional print environment have been studied for many years, the electronic environment presents a new and relatively unexplored area for such study. This article describes a citation analysis of research articles from scholarly electronic journals published in 1999-2000. The analysis focused on the extent to which scholars are using electronic resources and the types and subject areas of online resources that are being referenced. Results indicate a growing reliance on electronic resources by scholars, a high occurrence of nontraditional types of resources, and a relatively high use of interdisciplinary references.
\end{abstract}

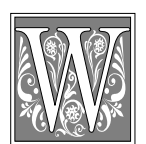

e are facing a radical change in the way people find and use information resources, a change that all information professionals need to understand. Much research has been done on the information-gathering behavior of various groups (for example, David Ellis ${ }^{1}$; Gloria J. Leckie, Karen E. Pettigrew, and Christian Sylvain²; and William Sugar ${ }^{3}$ ), so we have a reasonably good idea of how and why scholars use traditional print-on-paper and personal resources. Now, that work needs to be expanded to understand how the electronic revolution is changing information selection and use patterns. How has the proliferation of electronic resources changed researchers' information use? What kinds of online resources are researchers using? Does the diversity of the online environment and its search tools encourage researchers to go beyond the traditional resources of their disciplines?

The exploratory study described here, a citation analysis of references from a sample of research articles published in electronic journals during the 1999-2000 publication year, is an attempt to answer these questions. It provides a new look at a changing information environment and its impact on scholarly research activity.

\section{Review of the Literature}

Some early effects of the increasing availability of electronic resources are already apparent. As Jeffrey MacKie-Mason, Maria S. Bohn, Juan F. Riveros, and Wendy P. Lougee wrote, "Electronic access to scholarly journals has become an important and commonly accepted tool for researchers." ${ }^{4}$ According to Lawrence Rudner, digital libraries, when used efficiently, can be a boon to both researchers and practitioners, providing rapid access to both research findings and practical information. ${ }^{5}$

Major studies investigating the impact of e-journals on scholarly communication have been reported by Stephen P. Harter and by Harter and Hak Joon Kim. ${ }^{6-8}$ Using ISI's Journal Citation Reports to analyze the

Susan Davis Herring is the Engineering Reference Librarian and Associate Professor of Bibliography in the M. Louis Salmon Library at the University of Alabama in Huntsville; e-mail: herrings@email.uah.edu. 
citation patterns and impact factors of a sample of e-journals published between 1993 and 1995, these researchers attempted to determine the extent to which scholars were aware of e-journals and built their own work on research published in e-journals. Harter's analysis of thirty-nine e-journals found very little impact. Of the top five journals studied, three appeared in

\section{Articles in e-journals were more likely to cite electronic resources than were articles in print journals.}

both print and electronic form, making it impossible to determine the true impact of the e-journals. Overall, Harter concluded that "almost none of the scholarly, peerreviewed electronic journals in the sample have had a significant impact on formal communication in their respective fields." ${ }^{\prime 9}$

Harter and Kim analyzed a sample of citations from e-journals to determine the extent to which researchers publishing in e-journals relied on other electronic resources for their own research. Less than 2 percent of the total references in their study were to online sources, and only 0.2 percent were to e-journals. They concluded that "e-journals presently play almost no role in scholarly communication, as measured by references cited," but also noted that this might change over time. ${ }^{10}$

Two years later, in a study of the impact of Internet-based resources on scholarly communication in library and information science, Yin Zhang (1998) not only showed a higher impact rate, but also an increase in use over time. Almost 7.5 percent of the articles in Zhang's sample included references to online resources. In addition, articles in e-journals were more likely to cite electronic resources than were articles in print journals. Zhang noted that a different sample might show different results. ${ }^{11}$

One factor to consider in analyzing references to online sources is the type of resource being cited. Examining how individual scholars are invoked on the Web, Blaise Cronin, Herbert W. Snyder, Howard Rosenbaun, Anna Martinson, and Ewa Callahan pointed out that "The defining feature of the Web, hypertexuality, affords the possibility of multiple modes of mentioning or linking to a named individual and/or related cognitive resources."12 Their research identified eleven categories of Web-based documents linked to scholarly research, including electronic articles, conference papers, home pages, syllabi, and book reviews. Harter and Kim listed fourteen different types of sources found in their citation analysis. These included Web pages, personal papers, e-journal articles, e-mail, listservs, and local files, plus a large category of "not determined."13

The variation in types of resources found in electronic research may reflect the more porous disciplinary boundaries of Internetbased searching. As Cronin and Hert have pointed out, the Web supports browsing and discovery by scholars, well beyond the typical, traditional bibliographic tools from well-defined bodies of literature. ${ }^{14}$ Because most commonly used Web search engines are not subject specific, sites and pages found using these search engines will not be limited by the disciplinary confines and expectations of the searcher.

\section{Methodology}

The research described here focused on the following three questions:

1. To what extent are scholarly researchers using electronic resources in their research?

2. What types of electronic resources are being used?

3. Do the electronic resources that are being used reflect the interdisciplinary potential of the Web?

As mentioned above, some initial research has examined the impact of electronic resources on scholarly communication by analyzing citations in electronic journals. The current study follows both Harter and Kim, and Zhang in assuming that researchers who publish in e-journals are familiar with at least some online resources and have accepted such resources in their own research.

The data for this study were drawn from a selective sample of scholarly, peerreviewed e-journals available through the 
Web without subscription or registration. A total of twelve journals were selected representing areas of active interdisciplinary research, namely:

- library and information science (LIS/IS)

- gender studies

- ecology

- psychology

- religion and society

- computer-mediated communication (CMC)

- educational technology

- law and technology

All articles published in these twelve journals during a one-year period covering approximately summer 1999 through spring 2000 were examined (the time period varied because of different publication schedules), and all peer-reviewed research articles that included reference citations were selected. A total of 175 articles were identified.

The references listed for each article were examined, and duplicate references in each individual list were removed. Data concerning each article, including total number of unique citations, number of electronic citations, and subject discipline affiliations of the authors, were entered into a spreadsheet. Attempts were made to view each of the electronic resources. Information about each electronic citation, including type of resource and general discipline category, was entered into the spreadsheet for analysis.

\section{Research Results}

The 175 articles examined had a total of 4,289 unique references. Slightly over 55 percent of the articles in the sample (97 out of 175) cited electronic resources; 685 citations, or 16 percent of the total, were to electronic resources. All of the journal subject areas included articles with references to electronic resources, although the distribution varied by discipline as is shown in table 1 .

The ninety-seven articles that referenced electronic resources had a total of 2,584 unique citations, 26.5 percent of which were to electronic resources. A total of 42.5 percent of the references were to articles in online periodicals, and almost 25 percent were to the same journal in which the article being analyzed appeared. (For the purpose of this study, articles were defined as publications in scholarly, peer-reviewed ejournals and in online newspapers and magazines. Scholarly articles comprised 73 percent of the total number of electronic articles cited.) The remainder of the references represented a broad array of types of resources, as shown in table 2.

Several categories within this list are worth examining in more detail. "Reports," research studies produced for specific purposes and organizations, represented just over 20 percent of all electronic resources cited. "Home pages," over 15 percent of the total, included personal Web sites, home pages of organizations or institutions, sites promoting or providing information about products and services, and project Web sites.

\begin{tabular}{|lccc|}
\hline \multicolumn{4}{c}{ TABLE 1 } \\
& Distribution of Electronic Resources & \\
\hline \hline Journal Subject & Total Articles & With Electronic Citations & Percent \\
\hline Computer-Mediated Comm. & 21 & 19 & $90.5 \%$ \\
Ecology & 16 & 8 & $50.0 \%$ \\
Education Technology & 22 & 9 & $40.9 \%$ \\
Gender Studies & 25 & 5 & $20.0 \%$ \\
Law \& Technology & 23 & 19 & $76.0 \%$ \\
Library/Info Science & 43 & 35 & $82.6 \%$ \\
Psychology & 9 & 1 & $11.0 \%$ \\
Religion \& Society & 16 & 1 & $6.3 \%$ \\
\hline Total & 175 & 97 & $55.4 \%$ \\
\hline
\end{tabular}


TABLE 2

Types of Electronic Resources Cited

\begin{tabular}{|lcc|} 
Type of Resource & $\begin{array}{c}\text { Number } \\
(\mathbf{n}=\mathbf{6 8 5})\end{array}$ & Percent \\
\hline Article from same journal & 169 & $24.7 \%$ \\
Reports & 138 & $20.1 \%$ \\
Article from different journal & 122 & $17.8 \%$ \\
Home pages & 105 & $15.3 \%$ \\
Conference papers & 32 & $4.7 \%$ \\
Papers & 32 & $4.7 \%$ \\
Standard/specification & 19 & $2.8 \%$ \\
Other & 17 & $2.5 \%$ \\
Books & 15 & $2.2 \%$ \\
Press releases & 10 & $1.5 \%$ \\
Seminar papers & 8 & $1.2 \%$ \\
Electronic databases & 7 & $1.0 \%$ \\
Bibliographies & 4 & $0.6 \%$ \\
Speech/address & 3 & $0.4 \%$ \\
Unknown & 2 & $0.3 \%$ \\
Note: Total comes to less than 100 percent due to rounding. \\
\hline
\end{tabular}

A large number of the Webbased resources (nearly $18 \%$ of the total) could not be accessed. The majority of those (seventy-eight) returned HTML 404 messages ("Page not found"), indicating either a dead link or a bad URL. In several cases, a connection was successful after obvious typographical errors in URLs had been corrected. When a connection attempt returned a "Page not available" message, further attempts were made during a period of one week. If the connection still failed after that time, the resource was coded "not available/ not accessible." URLs that returned "Forbidden" messages or asked for a user ID and password also were coded as "not available/not accessible."

The authors in the sample represented a wide variety of subject

"Papers" consisted of textual documents not categorized elsewhere and not formally published. The "Other" category included class syllabi, slide presentations, tables without accompanying text, and similar items. The two items categorized as "Unknown" could neither be accessed nor identified from the citations.

\section{The development of the Internet has vastly enhanced the ability of research- ers to find and use sources that previ- ously would have been unavailable.}

For comparison, the print resources cited were analyzed by type as well. Books comprised 45.2 percent of the print citations and articles made up another 43.4 percent, accounting for nearly 90 percent of the total references. Of the remaining citations, 6 percent were conference papers, 3 percent were reports, and 1.1 percent were unpublished documents, primarily theses and dissertations. Personal communications, media (film, television, and recordings), laws and court cases, standards, speeches, and press releases each made up less than 1 percent of the references. disciplines. (When an article had authors from more than one subject discipline, only the first two disciplinary areas were considered.) However, as might be expected, authors' works tended to cluster within publications focused in their disciplinary affiliation. Table 3 shows the affiliations of the majority of authors in each journal category. Three of the eight categories-Library and Information Science, Gender Studies, and Computer-Mediated Communication (CMC)-evidenced strong interdisciplinarity, with authors from more than one subject area sharing the majority.

The electronic citations in the articles studied also tended to cluster within disciplinary areas representative of the journal subjects. However, some categories showed much more interdisciplinary use of electronic resources than did others. Gender Studies and Ecology were tightly focused; Library and Information Science, although exhibiting a greater spread of topic resources, still exhibited a tighter focus than did CMC, Educational Technology, or Law and Technology. The leading subject areas for each of these journal topics are shown in table 4 . The categories of Religion and Society and Psychology of Language, each 
with only one article citing electronic resources, are excluded in tables 4 and 5 .

Assuming that authors tend to select citations from the subject area with which they are most familiar (i.e., their own disciplines) and that the subjects with the highest number of citations represent the primary discipline areas for each journal, it is possible to define citations from other subject areas as representing interdisciplinary resources. Table 5 shows the percentages of same-discipline and cross-discipline electronic resource citations for the journals studied. Overall, 27 percent of the total electronic citations can be categorized as interdisciplinary.

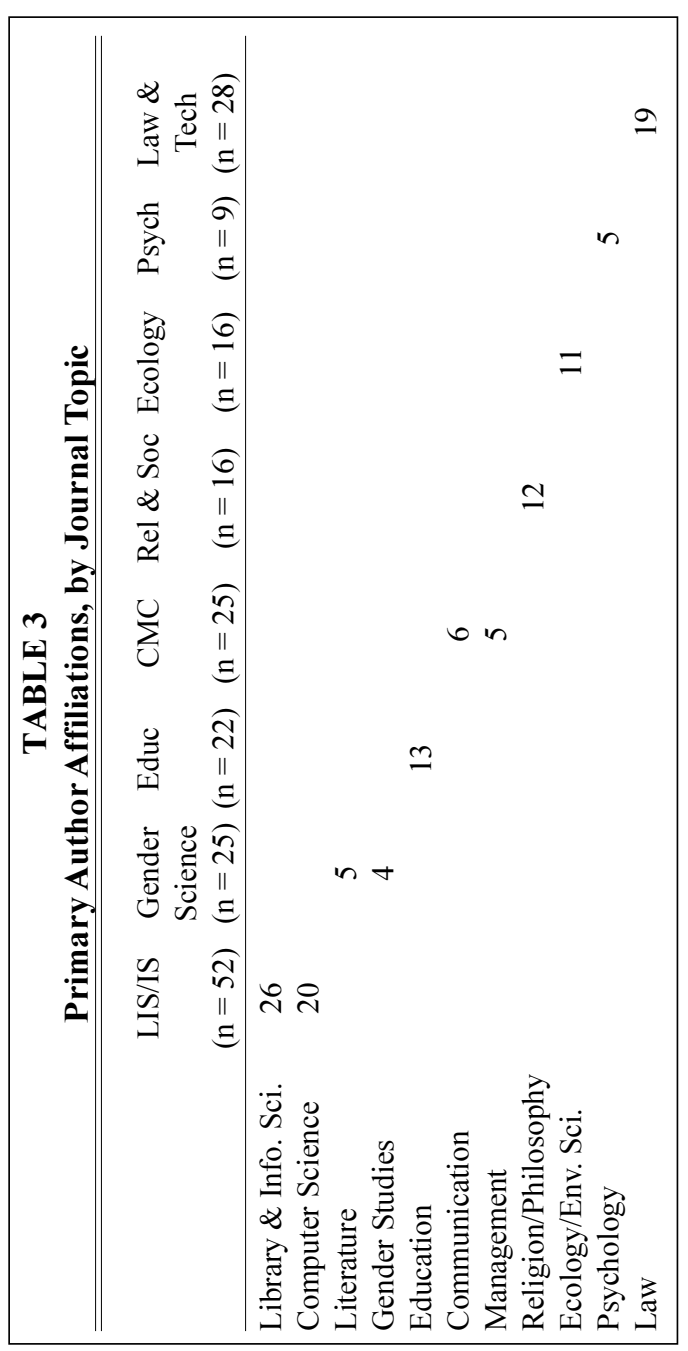

\section{Findings}

As mentioned previously, earlier research into the effect of electronic resources on scholarly research has shown relatively low impact. In their analysis of articles published in e-journals in 1995, Harter and Kim found that 1.9 percent of the total references were to electronic resources. ${ }^{15}$ Zhang, studying LIS journals published from 1994 through 1996, found that 7.49 percent of the articles included electronic references, but only 1.13 percent of the total references were to electronic resources. ${ }^{16}$ Herring, examining articles focusing on Internet search engine design in 1996, found that 2.1 percent of the total references were to electronic resources. ${ }^{17}$ The current study, focusing exclusively on ejournals, shows that more than half of the articles studied included electronic references and that 16 percent of the total references were to electronic resources.

It is generally assumed that most scholars typically select journal articles, monographs, and conference papers as their references, with the occasional personal communication, unpublished paper, or manuscript reference added. Indeed, this was the pattern found in the printed resources cited in the articles studied in this citation analysis. However, the pattern of documents found among the electronic resources in this study was quite different and reflected a much greater range of types of publications.

The development of the Internet has vastly enhanced the ability of researchers to find and use sources that previously would have been unavailable. Almost any competent Internet searcher can now access working papers, unpublished reports and studies, government papers, and other "gray literature" that previously would have been unknown and inaccessible. Data from Herring's 1999 study of articles on the design of Web search engines indicates that only 6 percent 


\section{TABLE 4}

Leading Subjects of Electronic Resources Cited, by Journal Topic

\begin{tabular}{lccccc}
\hline \hline LIS/IS & $\begin{array}{c}\text { Gender } \\
\text { Studies }\end{array}$ & $\begin{array}{c}\text { Education } \\
\text { Technology }\end{array}$ & $\begin{array}{c}\text { Computer-Mediated } \\
\text { Communication }\end{array}$ & Ecology & $\begin{array}{c}\text { Law \& } \\
\text { Technology }\end{array}$ \\
\hline $\begin{array}{l}\text { Library \& } \\
\text { Information } \\
\text { Science }\end{array}$ & Activist Sites & Education & $\begin{array}{c}\text { Computer-Mediated } \\
\text { Communication }\end{array}$ & Ecology & $\begin{array}{c}\text { Law \& } \\
\text { Technology }\end{array}$ \\
$\begin{array}{l}\text { Digital } \\
\text { Libraries }\end{array}$ & Gender Studies & Psychology & Internet Technology & Education \\
$\begin{array}{l}\text { Computer } \\
\text { Science }\end{array}$ & & & $\begin{array}{c}\text { Business \& } \\
\text { Management }\end{array}$ & Law \\
\hline
\end{tabular}

of the total citations represented gray literature. ${ }^{18}$ In the current study, 345 of the electronic resources were to such unpublished or ephemeral resources. Although this accounts for only 8 percent of the total number of unique citations, it represents over 50 percent of the electronic resources cited and more than 13 percent of the total citations in articles referencing electronic resources. The body of research literature available has expanded exponentially for scholars using the Internet.

\section{Almost 18 percent of the electronic resources cited in the articles analyzed either were not found or could not be accessed.}

Over one-quarter $(27 \%)$ of the electronic resources cited in the current study were categorized as interdisciplinary or outside the primary discipline areas of the journals or the authors' affiliations. However, the direct effect of online resources on interdisciplinarity is unclear. Although it is tempting to assume that the same Internet search capabilities that lead researchers to a wide variety of types of documents also lead to more interdisciplinary resources, this cannot be supported without further research. All one can conclude is that the use of electronic resources appears to encourage some interdisciplinary resource use.

Both the use of electronic resources and the extent of interdisciplinarity in the resources used varied by discipline and au- thor. Obviously, the acceptance and use of Web resources depend upon the user. As Zhang has noted, this is strongly influenced by the recognition of online sources as legitimate by the particular scholarly community in which the user operates. ${ }^{19}$ Use of electronic resources outside the researcher's specific discipline may be even more strongly influenced by such acceptance. Further research is needed on this topic.

Finally, it is worth noting once again that almost 18 percent of the electronic resources cited in the articles analyzed either were not found or could not be accessed. This is an unfortunate, but common, situation in the online environment because of the instability of many electronic documents, inadequate or inaccurate citations, and less-thanrobust connections and equipment. Although inaccurate citations have always been found in reference lists, the transitory nature of many Internet documents only aggravates this situation.

\section{Conclusion}

The research described in this article confirms that online resources are increasingly important to today's scholars and researchers. This was an exploratory study using a nonrandom sample of articles and is inherently not generalizable. By examining a sample of articles published in e-journals, we may be looking at researchers who are at the leading edge of use and acceptance of electronic sources. However, the findings reflect the 


\begin{tabular}{|lccccccc|}
\hline \multicolumn{8}{c|}{ TABLE 5 } \\
Percentage of Disciplinary and Interdisciplinary Electronic Citations, \\
by Journal Topic
\end{tabular}

fact that a radical change in informationseeking behavior and information resource use is taking place as scholars and researchers become more comfortable and familiar with the resources available through the Web. An awareness of this change can only help us in preparing for the future. Online resources offer an exciting alternative to, and an expansion of, traditional research sources and tools. By understanding how scholars use these resources, librarians and other information professionals will be able to provide enhanced service to their users.

\section{Notes}

1. David Ellis, "Modeling the Information-seeking Patterns of Academic Researchers: A Grounded Theory Approach," Library Quarterly 63 (Oct. 1993): 469-86.

2. Gloria J. Leckie, Karen E. Pettigrew, and Christian Sylvain, "Modeling the Information Seeking of Professionals: A General Model Derived from Research on Engineers, Health Care Professionals, and Lawyers," Library Quarterly 66 (Apr. 1996): 161-93.

3. William Sugar, "User-centered Perspective of Information Retrieval Research and Analysis Methods," Annual Review of Information Science and Technology 30 (1995): 77-109.

4. Jeffrey K. MacKie-Mason, Maria S. Bohn, Juan F. Riveros, and Wendy P. Lougee, "A Report on the PEAK Experiment," D-Lib Magazine 5, no. $7 / 8$ (July/Aug. 1999). Available online from http://www.dlib.org/dlib/july99/mackie-mason/07mackie-mason.html

5. Lawrence Rudner, "Who Is Going to Mine Digital Library Resources? And How?" D-Lib Magazine 6, no. 5(May 2000). Available online from http:/ /www.dlib.org/dlib/may00/rudner/05rudner.html.

6. Stephen P. Harter, "The Impact of Electronic Journals on Scholarly Communication: A Citation Analysis," Public-Access Computer Systems Review 7, no. 5 (1996). Available online from http://info.lib.uh.edu/pr/v7/n5/hart7n5.html.

7. - "Scholarly Communication and Electronic Journals: An Impact Study," Journal of the American Society for Information Science 49, no. 6 (May 1998): 507-16.

8. Stephen P. Harter and Hak Joon Kim, "Electronic Journals and Scholarly Communication: A Citation and Reference Study." Paper presented at the Midyear Meeting of the American Society for Information Sciences, May 20-22, 1996. Available online from http:// ezinfo.ucs.indiana.edu/ harter/harter-asis96midyear.html.

9. Harter, "Scholarly Communication and Electronic Journals," 515.

10. Harter and Kim, "Electronic Journals and Scholarly Communication," np.

11. Yin Zhang, "The Impact of Internet-based Electronic Resources on Formal Scholarly Communication in the Area of Library and Information Science: A Citation Analysis," Journal of Information Science 24, no. 4 (July/Aug. 1998): 241-54.

12. Blaise Cronin, Herbert W. Snyder, Howard Rosenbaun, Anna Martinson, and Ewa Callahan, "Invoked on the Web," Journal of the American Society for Information Science 49, no.14 (Dec. 1998): 1319-28.

13. Harter and Kim, "Electronic Journals and Scholarly Communication," np.

14. Blaise Cronin and C. A. Hert, "Scholarly Foraging and Network Discovery Tools," Journal of Documentation 51, no. 4 (Dec. 1995): 388-403.

15. Harter and Kim, "Electronic Journals and Scholarly Communication," np.

16. Zhang, "The Impact of Internet-based Electronic Resources," 245-50.

17. Susan Davis Herring, "The Value of Interdisciplinarity: A Study Based on the Design of Internet Search Engines," Journal of the American Society for Information Science 50, no. 4 (Apr. 1999): 358-65.

18. Herring, "The Value of Interdisciplinarity," 361.

19. Zhang, "The Impact of Internet-based Electronic Resources," 252-53. 